\title{
Do the benefits of Moringa oleifera trees extend to KELEA activation of water?
}

\begin{abstract}
Throughout history certain plants have been identified as having rather remarkable medical benefits often covering a wide range of illnesses. A prominent example is the Moringa oleifera tree. Consumption of the leaves of this tree is stated to reduce the severity of over one hundred different diseases. While undoubtedly a rich source of nutrients, the observed clinical benefits cannot easily be explained in terms of regular cellular biochemistry. An alternative cellular energy (ACE) pathway has been differentiated from the photosynthetic process of plants (and certain bacteria) and from the cellular energy obtained from food metabolism. The ACE pathway is envisioned as an inducible dynamic quality of the body's fluids resulting from the absorption of an environmental force termed KELEA (kinetic energy limiting electrostatic attraction). This paper expresses the opinion that the medicinal properties of plants such as Moringa oleifera are mediated in large part by their capacity to capture KELEA from the environment and transfer the absorbed energy to water. This explanation is consistent with the planned productive use of extracts of Moringa oleifera leaves and seeds in agriculture.
\end{abstract}

Keywords: moringa oleifera, water, kinetic energy limiting electrostatic attraction, alternative cellular energy, kiko, volcanic rock, ashitaba, humic acid
Volume 2 Issue I - 2015

\author{
W John Martin \\ Institute of Progressive Medicine, South Pasadena, USA
}

Correspondence: W John Martin, Institute of Progressive Medicine, 1634 Spruce Street, South Pasadena, CA 91030, USA, Tel 626-616-2868, Email wjohnmartin@ccid.org

Received: January 02, 2015 | Published: January 14, 2015
Abbreviations: KELEA, kinetic energy limiting electrostatic attraction; ACE, alternative cellular energy; HSV, herpes simplex virus; HZV, herpes zoster virus; HPV, human papillomavirus; COPD, chronic obstructive pulmonary disease

\section{Introduction}

The Moringa oleifera tree is indigenous to India but is now widely grown in many tropical areas of the world. ${ }^{1,2}$ It grows rapidly from both planted cuttings and seeds and its deep penetrating primary root allows for survival in arid climates. The widespread cultivation of Moringa trees, including for personal use, has been encouraged primarily as a source of edible protein, vitamins, essential lipids and minerals. ${ }^{3-6}$

Many clinical benefits have been ascribed to consuming leaves and leaf extracts of the Moringa oleifera tree. ${ }^{7-14}$ It is reported to alleviate various skin and systemic infections, asthma, arthritis, hypertension, peptic ulceration, diabetes, anxiety, depression, insomnia, heavy metal toxicity and most notably cancer. ${ }^{13,14}$ The toxicity of anti-cancer radiation and chemotherapy is also reduced and post-cancer surgery rehabilitation times are decreased. The healing of traumatic wounds is also expedited by the application of Moringa leaf powder. Pregnant women taking Moringa late in pregnancy have an earlier onset and increased production of breast milk following their child's birth. ${ }^{15}$

Efforts to attribute these and many other reported medicinal benefits of consuming Moringa leaves to its nutrients, including its more complex phytonutrients have generally failed to provide compelling supportive biochemical evidence. The author proposes a different interpretation that is based on an understanding of the ACE pathway.
This pathway was initially identified as providing a major defense against stealth adapted viruses. ${ }^{16-22}$ These viruses are not effectively recognized by the cellular immune system but can still be naturally suppressed both in patients and in virus cell cultures. The recovery is due to the production of cellular materials, which are commonly pigmented and can self-assemble into extracellular particles and fibers. ${ }^{16,19}$ The materials will commonly fluoresce, especially in conjunction with certain dyes including neutral red. They also display electrostatic and occasionally ferromagnetic properties. A striking feature of surviving infected in vivo and in vitro cells containing these materials is the major disruption of the cells' mitochondria; the main source of cellular energy from food metabolism. ${ }^{16,20}$ Along with other evidence such as tissue culture cell survival beyond a year without feeding, ${ }^{19}$ it was postulated that the materials were proving an energy pathway different from that of food metabolism. ${ }^{19}$ It was therefore, referred to as the ACE or third cellular energy pathway with photosynthesis being the first and food metabolism being the second. ${ }^{16}$ The particulate materials were appropriately called ACE pigments. ${ }^{19}$

Small numbers of ACE pigment particles added to fresh tissue culture medium can readily prevent the transient virus reactivation process, which typically follows replacement of the culture medium in "repaired" stealth adapted virus infected cultures. ${ }^{19}$ As discussed later, the particles do so by changing the dynamic quality of the tissue culture medium. Activation of the ACE pathway by directly applying neutral red dye to skin lesions caused by herpes simplex virus (HSV), herpes zoster virus (HZV) and human papillomavirus (HPV) leads to expedited healing of the lesions. ${ }^{23,24}$ As part of the healing process, the larger lesions will typically swell from the considerable ingress of fluid which can ooze from the lesions. ${ }^{24}$ Again, this can be attributed to fluid activation with lowered viscosity and heightened kinetic activity. 
It is now realized that the benefits of ACE pathway based therapies can extend well beyond the control of infectious diseases. At least in principle, enhancing the ACE pathway can compensate for all forms of insufficient cellular energy being available from food metabolism. These conditions can be broadly classified as i) inadequate oxygen as in chronic obstructive pulmonary disease (COPD); ii) impaired blood supply as in cardiovascular and cerebro-vascular diseases; iii) inefficient metabolism as in diabetes and iv) increased energy demands, as in infectious diseases and during wound healing.

As noted above, a case can be made for the expression of the ACE pathway as a dynamic property of the body's fluids. Various fluids including water and ethanol can be induced to more readily vaporize and to sustain an elevated vapor pressure in sealed containers by certain dipolar compounds. ${ }^{25}$ This activation can also be measured in comparison to non-activated corresponding fluids as an increased weight reduction in closed, but not completely sealed containers. Typical 6hour results for non-activated water is $<0.5 \mathrm{mg} / \mathrm{ml} \mathrm{compared}$ to the results of activated water, which exceed $>0.5 \mathrm{mg} / \mathrm{ml}$ and have even exceeded $5 \mathrm{mg} / \mathrm{ml}$. Another observation is that neutral red dye particles sprinkled onto activated water can show rather dramatic linear dissolving patterns with to-and-fro movements. This pattern contrasts with the slow and evenly expanding dye from stationary particles sprinkled onto non-activated water. Using such assays, various mineral-rich materials used in organic agriculture have shown water activating activity. These include humic and fulvic acids, zeolites, volcanic rocks, shungite (a product from Russia) and mica (unpublished). Heating to high temperatures $\left(\sim 1,000^{\circ} \mathrm{C}\right)$ can enhance their water activating properties. Kiko Technologies have used ground and heated volcanic rock material in the form of small pellets placed into perforated cartridges to conduct extensive farming studies. Using as few as 5 cartridges per acre, substantial increases in productivity and noticeable decreases in infestations have been recorded in controlled studies on both rice and sugarcane crops. ${ }^{26}$ Based on less well controlled field trials, humic and fulvic acids and zeolites have also successfully been used in many agricultural applications.

In discussions with Moringa growers, the author has learned of the common use of Moringa leaves to promote the growth and vitality of other crops. Water extracts of fresh Moringa leaves were said to be useful when sprayed onto other plants but that the activity tended to be lost over several days. This is consistent with water activation, since as noted above the weakly bonded water molecules will evaporate in closed, but not tightly sealed containers. Ongoing studies have further shown that heating of the Moringa leaf powder can increase its water activating activity, such that the Moring a components can be removed 1-2days later using a zero residue filter and yet the water stays active and may even increase in its activity. Studies to determine optimal heating conditions and water activating amounts of Moringa products, including seed extracts are currently underway. Comparisons are also being made with heated humic acids as well as other plant extracts, such as Ashitaba (Angelica keiskei) and cocoa. A widely used agricultural product from Japan termed HB-101 also provides a useful control. It is an aqueous extract from Japanese cedar, Hinoki cypress and Japanese red pine trees and from common plantain. For agricultural purposes it is used at 1:1,000 to 1:10,000 dilutions (www. hb-101.com).

A reason for focusing on Moringa is that, in addition to providing essential nutrients, it can potentially be used to create KELEA activated water for both human consumption and agricultural purposes. Moringa seeds are already widely used in the purification of drinking water by promoting the flocculation of various contaminants. ${ }^{27}$ This property may in fact be a direct reflection of Moringa induced loosening of hydrogen bonding between water molecules and molecular contaminants. The many prior clinical studies indicating benefits of ingesting Moringa leaves and leaf extracts ${ }^{7-15}$ can be retested using Moringa treated water from which the Moringa component has subsequently been removed by filtration. Agricultural studies can also compare the effectiveness of Moringa -derived materials in improving the quantity and quality of crops with the proven benefits of using ground and heated volcanic rocks. ${ }^{24}$

\section{Conclusion}

A new paradigm is emerging that the observed clinical and agricultural benefits of various compounds may actually be due to an induced dynamic quality of the water supporting living organisms. This had been clearly demonstrated with a device using pellets of ground, heated volcanic rock. A major focus in organic farming has been on humic and fulvic acids and zeolites, mined from the earth. Studies are planned to test whether their major benefits will also be through water activation rather than the provision of various minerals. The present article is intended to help broaden consideration of the scope of potential water activating products to include more readily available materials. Moringa trees are easy to cultivate and grow rapidly in many of the more underserved tropical countries. In addition to being a source of essential nutrients, it will be advantageous if their leaves and seeds can also be useful in the cultivation of additional crops and in improving the quality of drinking water. For ease of communication the term ACE Water is being introduced for water shown in controlled studies to enhance the ACE pathway, with its attended clinical and agricultural benefits.

\section{Acknowledgements}

I thank Manila Natures Link, Mr. Burl Gregory and Mr. Rodney Perdew for information regarding the cultivation and medical uses of Moringa.

\section{Conflict of interest}

The author declares no conflict of interest.

\section{References}

1. Villafuerte LR, Villafuerte Abonal L. Moringa: Malunggay Philippines. Singapore:Apples of Gold Publishing; 2009. 306 p.

2. Paliwal R, Sharma V, Pracheta V. A review on horse radish tree (Moringa oleifera): A multipurpose tree with high economic and commercial importance. Asian J Biotech. 2011;3(4):317-328.

3. Fuglie LJ. The Miracle Tree:Moringa oleifera: Natural Nutrition for the Tropics. Church World Service, Dakar. pp. 68; revised in 2001 and published as The Miracle Tree: The Multiple Attributes of Moringa; 1999. $172 \mathrm{p}$.

4. Marcu MG. Miracle Tree. Canada:KOS Health Publications; 2005. 172 p.

5. Machado DIS, Gastelum JAN, Moreno RC, et al. Nutritional quality of edible parts of Moringa oleifera. Food Anal Methods. 2010;3(3):175-180.

6. Kasolo JN, Bimenya GS, Ojok L, et al. Phyto chemicals and uses of Moringa oleifera leaves in Ugandan rural communities. J Medicinal Plants Res. 2010;4(9):753-757. 
7. Holst S. Moringa: nature's Medicine Cabinet. Sherman Oaks, USA: Sierra Sunrise Books; 2000. 122 p.

8. Fahey JW. Moringa oleifera: A review of the medicinal evidence for its nutritional, therapeutic, and prophylactic properties. Part 1. Trees for Life Journal. 2005;1:5

9. Anwar F, Latif S, Ashraf M, et al. Moringa oleifera: A food plant with multiple medicinal uses. Phytother Res. 2007;21(1):17-25.

10. Khawaja TM, Tahira M, Ikram UH. Moringa oleifera: a natural gift - A review. J Pharm Sci Res. 2010;2(11):775-781.

11. Abdull Razis AF, Ibrahim MD, et al. Health benefits of Moringa oleifera. Asian Pac J Cancer Prev. 2014;15(20):8571-8576.

12. Hussain S, Malik F, Mahmood S. Review:an exposition of medicinal preponderance of Moringa oleifera (Lank.). Pak J Pharm Sci. 2014;27(2):397-403.

13. Purwal L, Pathak AK, Jain UK. In vivo anticancer activity of the leaves and fruits of Moringa oleifera on mouse melanoma. Pharmacologyonline. 2010;1:655-665.

14. Berkovich L, Earon G, Ron I, et al. Moringa oleifera aqueous leaf extract down-regulates nuclear factor-kappaB and increases cytotoxic effect of chemotherapy in pancreatic cancer cells. BMC Complement Altern Med. 2013;13:212.

15. Estrella CP, Mantaring JVB, Grace Z, et al. A double-blind, randomized controlled trial on the use of malunggay (Moringa oleifera) for augmentation of the volume of breast milk among non-nursing mothers of preterm infants. Philippines J Pediatrics. 2000;49(1):3-6.

16. Martin WJ. The alternative cellular energy (ACE) pathway in the repair of the cytopathic effect (CPE) caused by stealth adapted viruses:In vitro and in vivo evidence supporting a new therapeutic paradigm, in Stealth Adapted Viruses; Alternative Cellular Energy (ACE) \& KELEA Activated Water. Indianna, USA: Author House; 2014. p. 31-70.
17. Martin WJ, Zeng LC, Ahmed K, et al. Cytomegalovirus-related sequences in an atypical cytopathic virus repeatedly isolated from a patient with the chronic fatigue syndrome. Am J Pathol. 1994;145(2):440-451.

18. Martin WJ. Stealth adaptation of viruses:Review and updated molecular analysis on a stealth adapted African green monkey simian cytomegalovirus (SCMV). J Hum Virol Retrovirol. 2014;1(4):1-14.

19. Martin WJ. Stealth virus culture pigments:A potential source of cellular energy. Exp Mol Pathol. 2003;74(3):210-223.

20. Martin WJ. Complex intracellular inclusions in the brain of a child with a stealth virus encephalopathy. Exp Mol Pathol. 2003;74(3):197-209.

21. Martin WJ. Progressive medicine. Exp Mol Pathol. 2005;78(3):218-220.

22. Martin WJ. Etheric biology. Exp Mol Pathol. 2005;78(3):221-227.

23. Martin WJ, Stoneburner J. Symptomatic relief of herpetic skin lesions utilizing an energy-based approach to healing. Exp Mol Pathol. 2005;78(2):131-134

24. Martin WJ, Stoneburner J. Alternative cellular energy (ACE) pathway activation as the mode of action of neutral red dye phototherapy of human viruses. J Hum Virol Retrovirol. 2014;1(4):1-8.

25. Martin WJ. KELEA activated water - enhancing the alternative cellular (ACE) pathway, in Stealth Adapted Viruses; Alternative Cellular Energy (ACE) \& KELEA Activated Water. USA: Author House Indiana; 2014. p. $115-144$.

26. Martin WJ. KELEA activated water leading to improved quantity \& quality of agriculture crops. Adv Plants Agric Res. 2015;2(1):1-5.

27. Ghebremichael KA, Gunaratna KR, Henriksson H, et al. A simple purification and activity assay of the coagulant protein from Moringa oleifera seed. Water Res. 2015;39(11):2338-2344. 